\title{
Matematização e ensino de Física: uma discussão de noções docentes
}

\author{
Mathematization and Physics teaching: \\ a discussion of teachers' notions
}

Gabriela Helena Geraldo Issa Mendes ${ }^{1}$. Irinéa de Lourdes Batista ${ }^{1}$

\begin{abstract}
Resumo: Este artigo é resultado de uma pesquisa que teve por objetivo investigar o papel da matematização na Física e no seu ensino, segundo professores de Física. Tendo em vista os estudos que evidenciam os benefícios da História e Filosofia da Ciência no ensino e na formação de professores, procuramos estabelecer alguns elementos que demonstram a presença de noções de História e Filosofia da Ciência na estruturação do conceito de matematização. Para tanto, elaboramos um questionário aberto que foi respondido por dez professores que lecionam disciplinas de Física. Para análise dos dados, adotamos a Análise de Conteúdo; a análise desses questionários resultou na estruturação de unidades temáticas que evidenciam as noções dos professores a respeito da matematização.
\end{abstract}

Palavras-chave: Matematização. História e filosofia da ciência. Ensino de física. Epistemologia. Análise de conteúdo.

\begin{abstract}
This article is the result of a research that aimed to investigate the role of mathematization in Physics and in its teaching. Considering the studies that demonstrate the benefits of History and Philosophy of Science in teaching and teacher education, it establishes some elements that demonstrate the presence History and Philosophy of Science notions in the structuring of the concept of mathematization. For that, we elaborated an open-questionnaire, answered by ten teachers of Physics. For data analysis, we adopt Content Analysis; from the analysis of the questionnaires, thematic units emerged that demonstrate the notions of teachers about mathematization.
\end{abstract}

Keywords: Mathematization. History and philosophy of science. Physics teaching. Epistemology. Content analysis.

\footnotetext{
${ }^{1}$ Universidade Estadual de Londrina (UEL), Programa de Pós-graduação em Ensino de Ciências e Educação Matemática, Londrina, PR, Brasil. E-mail: <gabrielaissa5@hotmail.com>.
} 


\section{Introdução}

Diariamente, professores que lecionam a disciplina de Física, tanto no Ensino Médio quanto no Ensino Superior, utilizam a Matemática para definir leis, conceitos e resolver exercícios. No entanto, conforme apresentaremos a seguir, muitos professores não conseguem definir o papel da matematização nem a relação entre a Matemática e a Física no ensino de Física.

Entendemos que a Matemática é uma linguagem e um processo epistemológico escolhidos pela Física para melhor e mais precisamente expressá-la. Poincaré (1854-1912), no início do século 20, já destacava esse papel da Matemática para o físico ao afirmar que:

[...] todas as leis, pois, provêm da experiência, mas para enunciá-la é preciso uma linguagem especial; a linguagem corrente é demasiado pobre, e aliás muito vaga para exprimir relações tão delicadas, tão ricas e tão preciosas. Eis portanto uma primeira razão pela qual o físico não pode prescindir da matemática; ela lhe fornece a única linguagem que ele pode falar (POINCARÉ, 1995, p. 91).

E, como qualquer linguagem, a Matemática, que tem seus próprios signos e sistema de representação consolidados, deve ser bem manejada pelos físicos e aprendizes de Física. Segundo Moreira (2003), dominar a linguagem de uma Ciência é a chave para a compreensão de um conhecimento ou de um conteúdo.

Entretanto, temos visto uma crise no ensino de Física devido ao mau uso da linguagem matemática. Em muitos casos, atribui-se o não aprendizado da Física à falta de domínio matemático, como salienta Pietrocola (2002, p. 90), dentre outros, ao afirmar que, “[...] no ensino de Física, a linguagem matemática é muitas vezes considerada a grande responsável pelo fracasso escolar".

Esse atributo de vilã, conferido à Matemática, é reflexo de um ensino de Física puramente matemático, cheio de fórmulas prontas e, muitas vezes, sem a discussão do porquê de se estar utilizando-as. Matthews (1995, p. 165) já alertava que um "[...] mar de falta de significação" tem "inundado as salas de aula de Ciências, [...] fórmulas e equações são recitadas sem que muitos cheguem a saber o que significam".

Nas Diretrizes Curriculares de Física do Paraná, há um alerta a respeito desse ensino de Física totalmente matematizado, afirmando que "[...] é reducionista e insuficiente ensinar Física, tão somente, por meio de questões como: considere, suponha, resolva e calcule" (PARANÁ, 2008, p. 67). Questões como essas, proporcionam um ensino tecnicista e acrítico, gerando a falsa sensação de uma Ciência pronta e acabada.

Batista (2004, p. 468) ressalta que "[...] a linguagem matemática tem sua própria lógica, que é relativamente independente da lógica de um processo físico e, por essa razão, reproduz o conteúdo físico indiretamente". Por essa razão, é preciso que professores e alunos saibam que Física não é Matemática e entender que a linguagem matemática não substitui o conhecimento físico.

A redução da Física à pura técnica, em certos casos; à técnica experimental e, em outros, à técnica matemática para a dedução lógica de consequências dos axiomas da teoria, evita questionamentos conceituais no seu ensino e gera uma formação limitada, estreita e acrítica. Assim, a investigação e o ensino da Física não devem ignorar simetricamente os avanços e os contrastes históricos que deram origem às ideias científicas atuais (BATISTA, 2004, p. 463). 
Diante do exposto, começamos a pensar em alternativas para amenizar essa crise no ensino de Física e acreditamos que a inserção da História e Filosofia da Ciência (HFC) seja uma delas.

Segundo a síntese apresentada por Matthews (1995, p. 165), a HFC não têm todas as respostas para todos os problemas, mas entre muitos benefícios, pode humanizar a Ciência e os cientistas, além de tornar as aulas mais desafiadoras, proporcionando um ensino crítico e reflexivo.

Uma queixa constante por parte de professores trata-se do grande desinteresse dos alunos nas aulas de Ciências, em que um dos motivos é o distanciamento do conteúdo ensinado com a realidade do estudante. E uma questão relevante é: como atrair o aluno à Ciência?

O contexto histórico, bem como o problema gerador, além de tornar o conteúdo mais interessante, mostra-se um importante recurso para tirar a impressão de que os cientistas eram gênios. Muitos alunos pensam que, em um belo dia, um cientista, que não tinha mais nada para fazer, acordou e disse: "vou inventar alguma coisa hoje". Bem sabemos que essa visão ingênua não retrata a realidade, e que um longo caminho de erros, debates coletivos e acertos foi trilhado pelos cientistas. O problema é que esse caminho complexo não é mencionado no ensino de Ciências e o aluno não sabe o porquê de tal teoria ou conteúdo existirem, nem como se chegou àquele resultado. Por essas razões, entende-se que

[...] uma discussão com abordagem histórico-filosófica recria o ambiente contextualizador que permite entender a origem da problemática, do desafio conceitual e/ou empírico - como se apresentaram as questões, as hipóteses, os elementos conflitantes - e os desenvolvimentos subsequentes, atingindo os conhecimentos procedimentais (os comos) além dos declarativos (o quê), para uma reestruturação fundamental, no sentido de ruptura com as bases conceituais e empíricas originais. (BATISTA, 2004, p. 473).

Mas, para que possamos experimentar esses benefícios proporcionados pela HFC no ensino de Ciências e Matemática, é preciso que os futuros professores tenham contato com a HFC em sua formação inicial. Segundo Matthews (1995, p. 185), “[...] um professor de Ciências com conhecimento de HFS pode auxiliar os estudantes a compreender exatamente como a Ciência apreende, e não apreende, o mundo real, vivido e subjetivo".

Há um ponto importante a ser destacado: todos os benefícios da História, Filosofia e Sociologia (HFC) citados neste artigo não serão efetivos se for apenas transmitida uma história linear, com muitas datas e especulações, premiando seus "pais" e os vencedores.

Outro ponto importante a destacar é que aula de História da Física não é aula de Física, nem aula de História da Matemática, aula de Matemática. Há de se ter preparo metodológico com bases científicas e utilizar a HFC como um instrumento contextualizador, que facilite a aprendizagem sem substituir os conteúdos do currículo. Abordar a HFC de uma forma coerente e planejada aumenta as chances de se obter benefícios no ensino e na aprendizagem. Por todas essas razões, defendemos a História da Ciência no ensino e na formação de professores.

Todavia, não basta a inserção da História da Ciência sem a devida discussão filosófica a respeito da Natureza da Ciência $(\mathrm{NdC})$.

Não há um consenso quanto à definição de Natureza da Ciência. Segundo Lederman (1992 apud LEDERMAN et al., 2002, p. 498, tradução nossa), "NdC refere-se à Epistemologia 
e Sociologia da Ciência, a Ciência como uma forma de saber, ou os valores e as crenças inerentes ao conhecimento científico e seu desenvolvimento".

Vázquez Alonso et al. (2007) apresentam questões que fazem referência à NdC, tais como:

[...] Que é ciência? Qual o seu funcionamento interno e externo? Como se constrói e desenvolve o conhecimento produzido pela ciência? Que métodos são usados para validar este conhecimento? Quais os valores implícitos nas atividades científicas? Qual é a natureza da comunidade científica? Quais foram e são as relações da ciência com a tecnologia até se constituir o atual sistema tecnocientífico? Quais são as relações da sociedade com este sistema? Quais são as contribuições para a cultura e progresso da sociedade? (VÁZQUEZ ALONSO et al., 2007, p. 128).

Essas questões aparecem com frequência em sala de aula. Alguns alunos sentem a necessidade de saber e entender essas questões; contudo, muitos docentes não estão preparados para promover discussões a respeito da $\mathrm{NdC}$. Esse despreparo por parte dos professores é consequência de uma formação com ausência de ou pobres discussões histórico-filosóficas da Ciência.

A falta de discussões a respeito da $\mathrm{NdC}$ acarreta uma série de noções equivocadas do conhecimento científico, tais como: acreditar que existe "o método científico", uma receita com procedimentos passo a passo seguida por todos os cientistas, o não entendimento de que o conhecimento científico é carregado de interpretações teóricas, entre outros.

Discussões acerca da NdC humaniza a Ciência e os cientistas, desmistificando-os, suprimindo a ideia de descoberta, de Ciência neutra e de um método infalível, dentre outros.

Tendo em vista a atual situação do Ensino de Física no Brasil e os benefícios proporcionados pela História e Filosofia da Ciência, decidimos investigar o papel da matematização na Física e em seu ensino, segundo docentes que lecionam disciplinas de Física.

\section{Epistemologia da Ciência e a Matematização}

A Epistemologia é um ramo da Filosofia, também conhecida como a teoria do conhecimento, que visa promover uma reflexão geral em torno da natureza, etapas e limites do conhecimento humano, ou seja, procura investigar como se dá a construção do conhecimento.

Segundo uma visão epistemológica, é possível promover reflexões e compreender o que se produz, como se produz, por que e para que se produz, tanto no que diz respeito ao conhecimento quanto à própria Ciência (LIMA, 2010).

Em busca do conhecimento e de compreender a natureza, pensadores da Ciência investigam meios de ajustar suas teorizações aos fenômenos físicos. Para tanto, recorrem aos conhecimentos matemáticos e iniciam um processo chamado de matematização da natureza. Estudos desde a Grécia antiga, como a conhecida Escola Pitagórica ( 550 a.C.), por exemplo, já apresentavam interpretações de fenômenos harmônicos por meio do processo de matematização. E essa matematização foi utilizada tanto para prever fenômenos quanto para compreender o movimento dos astros, ou ainda para orientar as navegações (BERNAL, 1975). 
Assim, entendemos que falar a respeito da matematização é falar acerca da epistemologia, sendo que a matematização não é tida como uma ferramenta, mas um processo na construção de um conhecimento científico.

\section{Matematização: uma visão geral}

Durante a revisão bibliográfica, procuramos conhecer o que autores da área pensavam a respeito do tema matematização. Dentre os artigos e livros encontrados, destacam-se as definições de matematização de alguns autores.

Hans Freudenthal (1905-1990), idealizador da "matemática realística", define matematização como a "organização da realidade com significado matemático" (1973 apud LUCCAS; BATISTA, 2011, p. 455).

Já Treffers e Goffree (1985, p. 100) a conceituam como “[...] uma atividade de organização e estruturação por meio da qual se adquire conhecimentos e habilidades para descobrir regularidades, conexões, e estruturas ainda desconhecidas".

Para Luccas e Batista (2011, p. 456), matematização consiste na “[...] atividade matemática que possibilita a organização e a estruturação dos fenômenos naturais pertencentes à realidade complexa, por meio de uma identificação de regularidades, padrões, relações e, posteriormente, estruturas matemáticas".

Segundo a pesquisadora francesa Roux (2010, p. 3, tradução nossa), “[...] a matematização refere-se à aplicação de conceitos, procedimentos e métodos desenvolvidos em matemática para os objetos de outras disciplinas ou, pelo menos, de outros campos do conhecimento".

Pietrocola (2002, p. 93), ao discutir o papel da Matemática na Física, diz que a matematização “[... ] se configura como uma 'tradução matemática', em que o cientista seria o tradutor pela sua capacidade de transitar entre os dois 'idiomas': da natureza e da Matemática".

Diante dessas definições, entende-se que a Matemática tem um papel estruturante e organizador, que possibilita identificar regularidades a fim de prever fenômenos, e que a matematização é um processo de tradução entre linguagens, representações de objetos, de adaptação e transformação de conhecimentos para que haja uma interface epistemológica entre diferentes domínios científicos e empíricos.

\section{A pesquisa empírica}

Para um estudo de caso específico na área de ensino de Física, em que buscamos desenvolver um estudo problematizado do atual quadro da realidade escolar e com o objetivo de conhecer as noções de professores de Física a respeito dessa temática, elaboramos e aplicamos um questionário para docentes que lecionam a disciplina de Física tanto no Ensino Médio quanto no Superior. Por meio dos registros dos discursos desses professores e fundamentados nos referenciais teóricos que subsidiaram a pesquisa, procuramos estabelecer alguns elementos que evidenciam a presença de conhecimentos de História e Filosofia da Ciência na estruturação do conceito de matematização, o papel desempenhado pela Matemática no ensino e seus desdobramentos. Assim, a pesquisa apresenta características qualitativas, uma vez que procuramos compreender e analisar o fenômeno pesquisado.

Optamos por um questionário semiestruturado, baseado nos seguintes objetivos. 
Objetivo geral: Conhecer as noções de professores de Física a respeito do conceito matematização.

\section{Objetivos específicos:}

- Identificar as possíveis contribuições da História e Filosofia da Ciência no processo de formação inicial de professores de Física; professores;

- Investigar o papel da Matemática no ensino de Física, segundo as noções desses

- Identificar os conteúdos matemáticos que os alunos apresentam maior dificuldade nas disciplinas de Física, tendo como fonte os professores.

Elaboramos questões abertas para dar oportunidade aos respondentes esclarecerem seus próprios pontos de vista, ao comentar, justificar e levantar hipóteses. Essa construção foi realizada pela pesquisadora responsável e decodificada intersubjetivamente pela coordenadora e membros do grupo de pesquisa Investigações em Filosofia e História da Ciência, Educação Científica e Matemática (IFHIECEM) ${ }^{2}$. Enunciamos a seguir, as dez perguntas que compuseram esse questionário.

1. Durante o processo de formação inicial, você participou de disciplinas específicas, ou correlatas, cursos complementares ou outros que tenham abordado noções de História da Ciência? Quais?

2. Comente a relação Física $\times$ Matemática no ensino de Física.

3. O saber matemático pode ser decisivo no aprender Física? Comente.

4. De acordo com sua experiência docente, no ensino de conteúdos físicos, qual o conteúdo matemático em que os alunos apresentam maior dificuldade? Você poderia levantar hipóteses do porquê desta dificuldade?

5. O que você viu/estudou a respeito do tema matematização na sua graduação?

6. O que você entende por matematização?

7. É possível diferenciar matematização de modelagem? Justifique sua resposta.

8. Cite um conteúdo físico que envolva um processo matematizado.

9. Quais os conteúdos matemáticos envolvidos no exemplo que você citou acima?

10. De acordo com seu exemplo, seria possível enunciar/desenvolver esse conteúdo utilizando outra linguagem que não seja a Matemática? De que maneira? Comente.

Para este artigo optamos em apresentar os dados das questões 1, 5 e 6 .

O questionário, bem como os detalhes e objetivos da pesquisa, foram enviados por e-mail para 30 professores, sendo que 12 retornaram com as respostas. Devido ao fato de que dois professores, dentre o rol de respondentes, mostraram-se não ter experiência em sala de aula, optamos em não analisar seus questionários. Por essa razão, foram analisados os dados de dez indivíduos.

Os professores participantes deste trabalho possuíam uma característica em comum e justamente por isso foram selecionados: lecionavam disciplinas de Física. Dentre eles, sete eram licenciados em Física, dois em Matemática e um possuía graduação em Engenharia Química. Em relação à pós-graduação, dois eram especialistas em Ensino de Matemática, dois em

\footnotetext{
${ }^{2}$ Disponível em: <http://www.uel.br/grupo-pesquisa/ifhiecem>. Acesso em: 7 jun. 2016.
} 
Ensino de Física, sete possuíam ou estavam cursando mestrado e dois possuíam ou estavam cursando doutorado.

Atendendo aos propósitos desta investigação, elegemos a Análise de conteúdo, fundamentada em Bardin (1979), para a análise e sistematização dos dados empíricos da pesquisa. Compreendemos a análise de conteúdo de Bardin como:

[...] um conjunto de técnicas de análise das comunicações visando obter, por procedimentos, sistemáticos e objetivos de descrição do conteúdo das mensagens, indicadores (quantitativos ou não) que permitam a inferência de conhecimentos relativos às condições de produção/recepção (variáveis inferidas) destas mensagens. (BARDIN, 1979, p. 42).

Optamos ainda por uma análise temática, que, segundo Bardin (1979, p. 77), refere-se à "[...] contagem de um ou vários temas ou itens de significação numa unidade de codificação previamente determinada". Assim, elaboramos previamente, para cada questão, Unidades de Análise, que compreenderam Unidades Temáticas de Contexto (UC), com suas respectivas Unidades Temáticas de Registro (UR). Adotamos o significado de Unidade de Registro e o de Unidade de Contexto como:

- Unidade de registro - É a unidade de significação a codificar e corresponde ao segmento de conteúdo a considerar como unidade de base, visando a categorização e a contagem frequencial. (BARDIN, 1979, p. 104).

- Unidade de contexto - A unidade de contexto serve de unidade de compreensão para codificar a unidade de registro e corresponde ao segmento da mensagem cujas dimensões (superiores às unidades de registro) são ótimas para que se possa compreender a significação exata da unidade de registro. (BARDIN, 1979, p. 107).

Assim como o questionário, as Unidades de Análise prévias foram elaborados pela pesquisadora com base no referencial teórico deste trabalho e decodificadas intersubjetivamente por integrantes do grupo de estudos e pesquisa IFHIECEM.

A seguir, apresentaremos as questões e suas respectivas Unidades Prévias. Para tanto, exibiremos o enunciado da questão, com suas respectivas Unidades Temáticas de Contexto (UC) e as Unidades Temáticas de Registro (UR) prévias, o objetivo da questão, a justificativa teórica, suas intenções, os trechos dos discursos dos professores participantes da pesquisa de acordo com a unitarização estruturada, e, por fim, a análise da mesma.

\section{Questão 1}

"Durante o processo de formação inicial, você participou de disciplinas específicas, ou correlatas, cursos complementares ou outros que tenham abordado noções de História da Ciência? Quais?"

A questão 1 teve por objetivo identificar se os professores receberam aportes históricos da Ciência em algum momento de sua formação inicial.

Consideramos como foco central dessa questão investigar a contribuição da História da Ciência na compreensão da Natureza da Ciência $(\mathrm{NdC})$, que, dentre muitos motivos já explicitados, propicia ao professor o conhecimento da sua Ciência, nesse caso, a Física. 
Assim, pretendemos investigar se as noções de História da Ciência contribuíram para a compreensão da matematização no processo de construção do conhecimento físico. Tal contribuição será investigada no decorrer das análises das próximas questões do questionário.

No Quadro 1, apresentamos os registros obtidos agrupados em suas correspondentes UR. Há também o número de registros e as frequências relativas ocorridas para cada uma das UR da UC1. Ressaltamos que a resposta do professor P2 foi desmembrada em duas Unidades distintas (1.1 e 1.2), por essa razão obtivemos 11 registros.

Quadro 1. Respostas das UR referentes à questão 1

\begin{tabular}{|c|c|}
\hline \multicolumn{2}{|c|}{ UC1 - Aportes históricos da Ciência na formação inicial } \\
\hline \multirow{2}{*}{$\begin{array}{l}\text { UR } 1.1 \text { Noções de História da } \\
\text { Ciência. }\end{array}$} & Frequência: 8 registros $(72,7 \%)$ \\
\hline & $\begin{array}{l}\text { P1, P7: Sim. Evolução dos conceitos e Teorias da Física. } \\
\text { P2: Sim. Disciplina de História e Filosofia da Ciência e da Matemática. } \\
\text { P4: Sim. Disciplina: História da Matemática e Noções Gerais da } \\
\text { Ciência. } \\
\text { P5: Tópicos de História da Física Moderna, Tópicos de História da } \\
\text { Física Clássica e Evoluçáo dos Conceitos da Física. } \\
\text { P8 e P9: História da Física. } \\
\text { P10: Estrutura dinâmica das teorias científicas. }\end{array}$ \\
\hline \multirow{2}{*}{$\begin{array}{l}\text { UR 1.2 Noções de História da } \\
\text { Ciência em disciplinas e/ou } \\
\text { atividades não específicas. }\end{array}$} & Frequência: 1 registro $(9,1 \%)$ \\
\hline & $\begin{array}{l}\text { P2: Curso de extensão: Introdução à História da Ciência e da } \\
\text { Matemática. }\end{array}$ \\
\hline \multirow{2}{*}{$\begin{array}{l}\text { UR } 1.3 \text { Ausência de aportes } \\
\text { históricos da Ciência. }\end{array}$} & Frequência: 2 registros $(18,2 \%)$ \\
\hline & $\begin{array}{l}\text { P3: Nenbuma disciplina. } \\
\text { P6: Não. }\end{array}$ \\
\hline $\begin{array}{l}\text { UR } 1.4 \text { Noções de História da } \\
\text { Ciência sem especificação. }\end{array}$ & Frequência: 0 registros $(0 \%)$ \\
\hline UR 1.5 Não contempla a pergunta. & Frequência: 0 registros $(\%)$ \\
\hline
\end{tabular}

Fonte: Mendes (2014, p. 83).

Como podemos obervar no Quadro 1, a maioria dos professores (72,7\%) receberam noções de História da Ciência em disciplinas específicas (UR 1.1), sendo que um deles $(9,1 \%)$ recebeu, também, tais noções por meio de um curso de extensão (UR 1.2). Apenas dois professores (18,2\%) afirmaram a ausência de aportes históricos (UR 1.3), sendo eles P3 e P6. Vale ressaltar que P3 tem graduação em Engenharia Química e P6, licenciatura em Física. 
Tendo em vista que as disciplinas de HC promovem discussões epistemológicas, elas podem possibilitar um contato com reflexões a respeito da Natureza da Ciência, que envolvem o processo de como o conhecimento científico se constrói e se desenvolve. Sendo a matematização parte integrante do processo de construção do conhecimento físico, acreditamos que tais disciplinas podem contribuir para o entendimento da matematização.

Sendo assim, esperamos, nas próximas Unidades, identificar nas respostas dos oito professores que receberam noções de História da Ciência elementos que evidenciem a contribuição desta na compreensão do processo de matematização.

\section{Questão 5}

"O que você viu/estudou a respeito do tema matematização na sua graduação?"

O objetivo da questão 5 era saber se os professores receberam noções a respeito do tema matematização na formação inicial.

Como já apresentado neste trabalho, o processo de matematização faz parte das discussões epistemológicas a respeito da natureza do conhecimento físico, sendo tais discussões essenciais na formação inicial do futuro professor. Segundo Adúriz-Bravo, Izquierdo e Estany (2002, p. 466, tradução nossa), “[...] a dimensão metacientífica (filosófica, a ciência histórica e sociológica) é um dos principais domínios do conhecimento profissional do professor, capaz de dar estrutura e coerência para as demais".

Diante disso, esperamos que os professores que receberam aportes de História da Ciência e/ou História e Filosofia da Ciência indiquem ter visto/estudado o tema matematização.

No Quadro 2, apresentamos os registros obtidos agrupados em suas correspondentes UR. Há também o número de registros e as frequências relativas ocorridas para cada uma das UR da UC5.

Com base no Quadro 2, constatamos que a maioria (60\%) afirmou não ter recebido noções a respeito do tema matematização na graduação e que um $(10 \%)$ professor respondeu de maneira confusa à pergunta, permitindo inferir que ele também não recebeu tais noções.

Dentre os três (30\%) que afirmaram ter recebido noções quanto ao tema em questão, um deles disse que "acredita ter estudado", denotando incerteza quanto ao assunto. P4 afirmou ter recebido essas noções de forma ampla, mas P2 diz se lembrar de alguns exemplos que se referem especificamente à Engenharia Cartográfica e Computação.

Podemos relacionar as respostas dadas pelos professores nesta questão com a primeira questão deste questionário, na qual os professores indicaram se cursaram disciplinas que abordaram noções de História da Ciência.

Os três professores (30\%) que afirmaram ter visto/estudado o tema matematização (UR 5.1) frequentaram disciplinas com noções de História e Filosofia da Ciência, mas o que chama atenção é que dois deles (P2 e P4) cursaram licenciatura em Matemática e apenas P10, licenciatura em Física.

$\mathrm{Na}$ sequência, podemos observar que, dos seis $(60 \%)$ professores que afirmaram não ter estudado o assunto em questão, P3 e P6 (20\%) foram os dois únicos professores que não receberam aportes históricos na formação inicial. P5 (10\%) afirmou ter cursado disciplinas de História da Física e Evolução dos Conceitos da Física, e P9 (10\%) cursou apenas História da Física. Outro ponto interessante a ser destacado é que P1 e P7 (20\%) afirmaram não ter estu- 
Quadro 2. Respostas das UR referentes à questão 5

\section{UC5 - Noções a respeito do tema matematização na formação inicial}

\begin{tabular}{|c|c|}
\hline \multirow{2}{*}{$\begin{array}{l}\text { UR 5.1 Noções do } \\
\text { tema matematização }\end{array}$} & Frequência: 3 registros $(30 \%)$ \\
\hline & $\begin{array}{l}\text { P4: De maneira ampla, no que diz respeito ao pensar matematicamente, ou seja, } \\
\text { pensar, raciocinar e trabalhar Matemática no nosso cotidiano. } \\
\text { P2: Lembro-me de alguns exemplos da Álgebra Linear com relação à programação } \\
\text { de imagens em engenharia cartográfica e computação. } \\
\text { P10: Acredito ter estudado durante a disciplina de estruturas das teorias, pois } \\
\text { estudamos o desenvolvimento de algumas teorias. }\end{array}$ \\
\hline \multirow{2}{*}{$\begin{array}{l}\text { UR } 5.2 \text { Ausência } \\
\text { de noções do tema } \\
\text { matematização }\end{array}$} & Frequência: 6 registros $(60 \%)$ \\
\hline & $\begin{array}{l}\text { P1: Não posso afirmar que vi esse tema de forma específica. Entretanto, ele foi } \\
\text { corrente ao longo de toda a graduação, quando utilizávamos a linguagem matemática } \\
\text { para analisar os problemas físicos nas diversas disciplinas. } \\
\text { P3: Absolutamente nada. Minha graduação foi um curso de bacharelado. } \\
\text { P5: Com o termo matematização, nada. Mas estudamos muitas coisas sobre a } \\
\text { Matemática. } \\
\text { P6, P9: Nada que eu me recorde. } \\
\text { P7: Bem, especificamente nada, mas nem precisaria, pois estava intrínseco nas aulas } \\
\text { e nas avaliações o grau elevado de matematização da Física. }\end{array}$ \\
\hline \multirow{2}{*}{$\begin{array}{l}\text { UR } 5.3 \text { Não contempla } \\
\text { a pergunta }\end{array}$} & Frequência: 1 registro $(10 \%)$ \\
\hline & $\begin{array}{l}\text { P8: Na graduação, aprendemos muitas fórmulas, elaborá-las também, por meio de } \\
\text { cálculo diferencial e integral aplicados a determinadas situaçôes da realidade física. }\end{array}$ \\
\hline
\end{tabular}

Fonte: Mendes (2014, p. 99).

dado o termo matematização, mas admitiram que as noções a respeito da matematização eram correntes ao longo do curso, pois estavam intrínsecas às aulas. Uma curiosidade é que P1 e P7 cursaram a mesma disciplina, Evolução dos conceitos e Teorias da Física, na mesma Universidade, a Universidade Estadual de Londrina (UEL). Já P8 (10\%), cuja resposta não contemplou a pergunta (UR 5.3), cursou a disciplina de História da Física.

Diante da relação entre essa questão e a primeira, inferimos que as disciplinas de História e Filosofia da Ciência estão diretamente ligadas ao fato de os professores afirmarem ter noções a respeito do tema matematização, e os professores que cursaram apenas História da Física não receberam, ou receberam de forma insatisfatória, tais noções. Uma hipótese seria uma História da Ciência transmitida de forma linear.

Concluímos que há um equívoco nos cursos de licenciatura em Física, pois, ao promover discussões histórico-filosóficas a respeito do processo de construção do conhecimento físico, 
o processo de matematização não é explicitado, ou pouco abordado, o que leva à hipótese de uma falha epistemológica a respeito da compreensão da Física.

\section{Questão 6}

"O que você entende por matematização?"

Por meio dessa questão, buscamos conhecer qual a compreensão dos professores a respeito da matematização.

No Quadro 3, apresentamos os registros obtidos agrupados em suas correspondentes UR. Há também o número de registros e as frequências relativas ocorridas para cada uma das UR da UC6.

Com base no Quadro 3, constatamos que todos os professores, inclusive os que não receberam noções a respeito da matematização, descreveram o que eles entendiam acerca desse tema.

Quadro 3. Respostas das UR referentes à questão 6

UC6 - Compreensão semântica da terminologia matematização

\begin{tabular}{|c|c|}
\hline \multirow{2}{*}{$\begin{array}{l}\text { UR } 6.1 \\
\text { Desconhecimento do } \\
\text { termo }\end{array}$} & Frequência: 0 registros (\%) \\
\hline & \\
\hline \multirow{2}{*}{$\begin{array}{l}\text { UR 6.2 Definição } \\
\text { segundo o consenso } \\
\text { científico atual }\end{array}$} & Frequência: 3 registros $(30 \%)$ \\
\hline & $\begin{array}{l}\text { P1: Matematizar é utilizar a linguagem matemática para expor e interpretar } \\
\text { conceitos diversos. } \\
\text { P6: Descrever matematicamente fenômenos e conceitos. } \\
\text { P8: Para mim, matematização é o processo de representação da realidade vivida por } \\
\text { meio de símbolos, a fim de estabelecer relações segundo determinados critérios. }\end{array}$ \\
\hline \multirow{2}{*}{$\begin{array}{l}\text { UR 6.3 Divergência } \\
\text { semântica }\end{array}$} & Frequência: 3 registros $(30 \%)$ \\
\hline & $\begin{array}{l}\text { P4: No mundo contemporâneo, onde a identidade digital se destaca a matematização } \\
\text { pode ser entendida como uma prática disciplinar que nos ensina a pensar logicamente. } \\
\text { P5: O indivíduo, de alguma forma, assimila intelectualmente o que vê/ ouve sobre a } \\
\text { matemática e passa a entender fenômenos do dia a dia a partir dessas assimilações. } \\
\text { P9: Seria a aplicação da Matemática em si junto ao ensino da teoria. Conceitos de } \\
\text { cálculos e operaçôes matemáticas. }\end{array}$ \\
\hline UR 6.4 Polissemia & Frequência: 1 registro $(10 \%)$ \\
\hline
\end{tabular}

P3: Explicar todo fenômeno por meio de conceitos matemáticos. 
Quadro 3. continuação

\begin{tabular}{|c|c|}
\hline \multicolumn{2}{|c|}{ UC6 - Compreensão semântica da terminologia matematização } \\
\hline \multirow{2}{*}{$\begin{array}{l}\text { UR } 6.5 \text { Não contempla } \\
\text { a pergunta }\end{array}$} & Frequência: 2 registros $(20 \%)$ \\
\hline & $\begin{array}{l}\text { P2: Compartilho com a educadora Maria Helena do Rio Grande do Sul-RS, } \\
\text { sobre o processo de matematização: "Na matematização, à medida que vamos } \\
\text { analisando informaçoes, saberes, transformando-os em gráficos, em linguagem } \\
\text { matemática, vamos compreendendo a razaão de ser das situaçôes problemáticas, por } \\
\text { que isso aconteceu, quem está por trás disso, a que contexto social estávamos e estamos } \\
\text { submetidos, o que os números, os gráficos revelam, apresentam implicitamente, o } \\
\text { que está por trás de cada dado numérico, de cada informação, matematicamente } \\
\text { representada" (p. 4). (Maria Helena Weschenfelder). } \\
\text { P10: O estudo de parte desse processo foi importante para o desenvolvimento das } \\
\text { relaçóes de variáveis que descrevem um dado fenômeno, assim como o desenvolvimento } \\
\text { bistórico de uma teoria. }\end{array}$ \\
\hline \multirow{2}{*}{$\begin{array}{l}\mathbf{U R E}^{3} \mathbf{6 . 6} \text { Incerteza na } \\
\text { resposta }\end{array}$} & Frequência: 1 registro $(10 \%)$ \\
\hline & P7: Usar a linguagem matemática? \\
\hline
\end{tabular}

Fonte: Mendes (2014, p. 102).

Apenas três $(30 \%)$ professores apresentaram uma definição segundo o consenso científico atual (UR 6.2). Entre os demais, três (30\%) apresentaram divergência semântica (UR 6.3) e um $(10 \%)$ descreveu a matematização de forma polissêmica. Percebemos que dois $(20 \%)$ professores ofereceram respostas que não contemplavam a pergunta, sendo que P2 tentou explicar a matematização por meio de uma citação que não apresenta uma definição, mas toda uma estrutura histórico-epistemológica que envolve o processo de matematização. Já P7 (10\%) mostrou incerteza na resposta, respondendo a questão com outra pergunta.

Isso nos leva a concluir que a maioria dos professores apresentam visões equivocadas a respeito da matematização e que as disciplinas de História e Filosofia da Ciência não foram suficientes para sua compreensão.

Esses dados são preocupantes e nos fazem refletir a respeito da epistemologia do professor e dos saberes docentes, pois percebemos uma distorção quanto ao entendimento da Física e ao processo de desenvolvimento dos conceitos e teorias. Será que os professores estão preocupados apenas com os conhecimentos do conteúdo? Quais são esses conhecimentos? O conhecimento docente é muito mais amplo do que apenas dominar um conteúdo técnico a ser ministrado em aula. É preciso que o professor faça reflexões teóricas e epistemológicas a respeito da sua Ciência. Segundo Shulman (1986, p. 9),

\footnotetext{
${ }^{3}$ Unidade de Registro Emergente.
} 
O professor precisa não somente compreender que algo é assim; o professor deve ainda compreender por que é assim, quais motivos justificam que isso pode ser afirmado, e sob quais circunstâncias nossa crença na justificação pode ser enfraquecida ou até mesmo negada. Além disso, nós esperamos que o professor compreenda porque um determinado tópico é particularmente central para uma disciplina enquanto um outro qualquer possa ser periférico.

Ressaltamos que a História da Ciência propicia a compreensão dos aspectos citados por Shulman (1986) e as disciplinas que abordam a HC também deveriam propiciá-los.

\section{Análise geral e considerações finais}

Com base em nossos dados empíricos, podemos inferir que os cursos de licenciatura em Física, e áreas afins, e as disciplinas com conteúdos de HFC formadores dos respondentes a essa pesquisa não foram suficientes para propiciar um conhecimento epistemológico estável a respeito do processo de como o conhecimento físico se constrói e se desenvolve matematicamente. Uma vez que a matematização é parte integrante do processo de construção do conhecimento físico e do inter-relacionamento entre a Física e a Matemática, nossa dedução vem do fato de que a maioria dos oito $(80 \%)$ professores que receberam noções de HFC não apresentou clareza e coerência quanto ao entendimento da matematização.

Um fato alarmante diz respeito ao tema matematização não ser abordado explicitamente na formação inicial. Dos três professores que afirmaram ter recebido noções a respeito da matematização, dois eram licenciados em Matemática e um era licenciado em Física, sendo que este último disse acreditar ter estudado o tema. Sendo a matematização um processo na construção do conhecimento físico, consideramos uma falha epistemológica a formação inicial não abordar explícita e recursivamente tal assunto nos cursos de Física.

Destacamos que, de um modo geral, os professores que receberam noções de História e Filosofia da Ciência (40\%) apresentaram melhor compreensão a respeito dos assuntos abordados do que os que receberam apenas noções de História da Ciência ou dos que não receberam tais noções. Esses dados corroboram as pesquisas e os autores citados neste trabalho, que afirmam que a História e a Filosofia da Ciência promovem a compreensão da Natureza da Ciência. Por essa razão, salientamos mais uma vez a importância da inserção dessas noções na formação inicial, ainda que nossos dados nos informem que a formação inicial disciplinar de nossos entrevistados não obteve sucesso efetivo de aprendizagem.

A investigação que realizamos colabora para as pesquisas que versam a respeito da História e Filosofia da Ciência na formação do professor e para a compreensão do processo de construção do conhecimento físico, no que se refere à matematização. Finalmente, consideramos que os resultados obtidos por meio dessa investigação trazem elementos relevantes para as pesquisas que visam a um incremento e aperfeiçoamento em noções docentes e matematização no ensino de Física. 


\section{Referências}

ADÚRIZ-BRAVO, A.; IZQUIERDO, M.; ESTANY, A. Una propuesta para estructurar la enseñanza de la filosofía de la ciencia para el profesorado de ciencias en formación. Enseñanza de las Ciencias, Barcelona, v. 20 n. 3, p. 465-476, 2002. Disponível em: <http://www.raco.cat/index.php/Ensenanza/article/download/21839/21673>. Acesso em: 8 jun. 2016.

BARDIN, L. Análise de conteúdo. São Paulo: Edições 70, 1979.

BATISTA, I. L. O ensino de teorias físicas mediante uma estrutura histórico-filosófica. Ciência \& Educação, Bauru, v. 10, n. 3, p. 461-476, 2004. Disponível em: < http:/ /www. scielo.br/pdf/ciedu/v10n3/10.pdf >. Acesso em: 8 jun. 2016.

BERNAL, J. D. Ciência na história. Lisboa: Livros Horizonte, 1975.

LEDERMAN, N. G. et al. Views of nature of science questionnaire: toward valid and meaningful assessment of learners' conceptions of nature of science. Journal of Research in Science Teaching, Hoboken, v. 39, n. 6, p. 497-521, 2002.

LIMA, P. G. Ciência e epistemologia: reflexões necessárias à pesquisa educacional. Quaestio: revista de estudos em educação, Sorocaba, v. 12, n. 2, p. 109-138, 2010.

Disponível em: <http://periodicos.uniso.br/ojs/index.php?journal=quaestio\&page=article \&op=view\&path $\% 5 B \% 5 \mathrm{D}=195>$. Acesso em: 8 jun. 2016.

LUCCAS, S.; BATISTA, I. L. O papel da matematização em um contexto interdisciplinar no ensino superior. Ciência \& Educação, Bauru, v. 17, n. 2, p. 451-468, 2011. Disponível em: <http:/ /dx.doi.org/10.1590/S1516-73132011000200013>. Acesso em: 8 jun. 2016.

MATTHEWS, M. R. História, filosofia e ensino de ciências: a tendência atual de reaproximação. Caderno Catarinense de Ensino de Física, Florianópolis, v. 12, n. 3, p. 164-214, 1995. Disponível em: <https://periodicos.ufsc.br/index.php/fisica/article/ view/7084/6555>. Acesso em: 8 jun. 2016.

MENDES, G. H. G. I. Matematização e ensino de física: uma discussão de noções docentes. 2014. 132 f. Dissertação (Mestrado em Ensino de Ciências e Educação Matemática) - Universidade Estadual de Londrina, Londrina, 2014.

MOREIRA, M. A. Linguagem e aprendizagem significativa. In: ENCONTRO

INTERNACIONAL LINGUAGEM, CULTURA E COGNIÇÃO, 2., 2003, Belo Horizonte. Disponível em: <www.if.ufrgs.br/ moreira/linguagem.pdf>. Acesso em: 23 jul. 2012.

PARANÁ. Secretaria de Estado da Educação. Diretrizes curriculares da educação básica: física. Curitiba, 2008. Disponível em: < http://www.educadores.diaadia.pr.gov.br/arquivos/ File/diretrizes/dce_fis.pdf>. Acesso em: 27 jul. 2012.

PIETROCOLA, M. A matemática como estruturante do conhecimento físico. Caderno Catarinense de Ensino de Física, Florianópolis, v.19, n.1, p. 89-109, 2002. Disponível em: <https://periodicos.ufsc.br/index.php/fisica/article/view/9297>. Acesso em: 8 jun. 2016. POINCARÉ, H. O valor da ciência. Rio de Janeiro: Contraponto, 1995. 
ROUX, S. Forms of mathematization $\left(14^{\text {th }}-17^{\text {th }}\right.$ centuries $)$. Early Science and Medicine, Leiden, v. 15, n. 4-5, p. 319-337, 2010.

SHULMAN, L. S. Those who understand: knowledge growth in teaching. Educational Researcher, Washington, v. 15, n. 2, p. 4-14, 1986.

TREFFERS, A.; GOFFREE, F. Rational analysis of realistic mathematics education: the Wiskobas program. In: STREEFLAND, L. (Ed.). Proceedings of the Ninth International Conference for the Psychology of Mathematics Education: individual contributions. Utrecht: University of Utrecht, 1985. v. 2, p. 97-121.

VÁZQUEZ ALONSO, A. et al. Consensos sobre la naturaleza de la ciencia: la comunidad tecnocientífica. Revista Electrónica de Enseñanza de las Ciencias, Vigo, v. 6, n. 2, p. 331-363, 2007. Disponível em: <http://reec.uvigo.es/volumenes/volumen6/ART7_Vol6_ N2.pdf $>$. Acesso em: 8 jun. 2016. 